\title{
Management of patients with multidrug-resistant tuberculosis
}

\author{
C. Lange, R. E. Aarnoutse, J. W. C. Alffenaar, G. Bothamley, F. Brinkmann, J. Costa, D. Chesov, R. van \\ Crevel, M. Dedicoat, J. Dominguez, R. Duarte, H. P. Grobbel, G. Günther, L. Guglielmetti, \\ J. Heyckendorf, A. W. Kay, O. Kirakosyan, O. Kirk, R. A. Koczulla, G. G. Kudriashov, L. Kuksa, F. van \\ Leth, C. Magis-Escurra, A. M. Mandalakas, B. Molina-Moya, C. A. Peloquin, M. Reimann, \\ R. Rumetshofer, H. S. Schaaf, T. Schön, S. Tiberi, J. Valda, P. K. Yablonskii, K. Dheda \\ Please see Supplementary Data for details of all author affiliations.
}

S U M M A R Y

The emergence of multidrug-resistant tuberculosis (MDR-TB; defined as resistance to at least rifampicin and isoniazid) represents a growing threat to public health and economic growth. Never before in the history of mankind have more patients been affected by MDRTB than is the case today. The World Health Organization reports that MDR-TB outcomes are poor despite staggeringly high management costs. Moreover, treatment is prolonged, adverse events are common, and the majority of affected patients do not receive adequate treatment. As MDR-TB strains are often resistant to one or more second-line anti-TB drugs, in-depth genotypic and phenotypic drug susceptibility testing is needed to construct personalised treatment regimens to improve treatment outcomes. For the first time in decades, the availability of novel drugs such as bedaquiline allow us to design potent and well-tolerated personalised MDR-TB treatment regimens based solely on oral drugs. In this article, we present management guidance to optimise the diagnosis, algorithm-based treatment, drug dosing and therapeutic drug monitoring, and the management of adverse events and comorbidities, associated with MDRTB. We also discuss the role of surgery, physiotherapy, rehabilitation, palliative care and smoking cessation in patients with MDR-TB. We hope that incorporating these recommendations into patient care will be helpful in optimising treatment outcomes, and lead to more MDRTB patients achieving a relapse-free cure.

KEY WORDS: MDR-TB; RESIST-TB; TBNET; TB; XDR-TB; personalised treatment
TUBERCULOSIS (TB) IS an airborne infectious disease caused by Mycobacterium tuberculosis. The World Health Organization (WHO) estimates that approximately 10.0 million people developed TB, and 1.6 million people died from the disease in $2017 .{ }^{1}$ TB is the leading cause of death attributed to a single micro-organism worldwide.

The emergence of drug-resistant strains of $M$.

Previous articles in the series Editorial: Horsburgh C. The MDR-TB epidemic — a status report. Int J Tuberc Lung Dis 2019; 23: 121. Articles: No 1: Cox V, Cox H, Pai M, Stillo J, Citro B, Brigden G. Health care gaps in the global burden of drug-resistant tuberculosis. Int J Tuberc Lung Dis 2019; 23: 125-135. No 2: Nathavitharana R R, Lederer P, Tierney D B, Nardell $E$. Treatment as prevention and other interventions to reduce transmission of multidrug-resistant tuberculosis. Int J Tuberc Lung Dis 2019; 23: 396-404. No 3: E. A. Kendall, S. Sahu, M. Pai, et al. What will it really take to eliminate drug-resistant tuberculosis? Int J Tuberc Lung Dis 2019; 23: 535-546. tuberculosis has complicated TB control and subverted the goals of the WHO's End TB Strategy $195 \%$ reduction in deaths due to $\mathrm{TB}$ and a $90 \%$ reduction in TB incidence rate by the year 2035 compared to 2015). ${ }^{2}$ According to WHO TB reports, the number of patients with a confirmed diagnosis of multidrugresistant TB (MDR-TB; defined as resistance of $M$. tuberculosis to at least rifampicin [RMP] and isoniazid [INH]) has increased in the past years from $\sim 84000$ in 2012 to $\sim 153000$ in $2017 .{ }^{1}$ This development is only partly explained by better diagnostic capacities. The estimated total burden of patients with MDR-TB is much higher and has increased from 450000 in 2012 to 458000 in 2017.1 Extensively drug-resistant TB (XDR-TB), defined as MDR-TB plus resistance to a fluoroquinolone (FQ) and at least one second-line injectable

Correspondence to: Christoph Lange, Clinical Infectious Diseases, Research Center Borstel, Parkallee 35, 23845 Borstel, Germany. e-mail: clange@fz-borstel.de

Article submitted 9 September 2018. Final version accepted 2 January 2019. 
agent (amikacin [AMK], capreomycin [CPM] or kanamycin $[\mathrm{KM}])$, was identified in patients from 127 countries in $2017 .{ }^{1}$

The highest estimated prevalence of MDR-TB is in India and China. However, the largest number of patients who have been diagnosed with MDR-TB live in the European Region of the WHO. In Belarus, Kazakhstan, Kyrgyzstan, the Republic of Moldova, the Russian Federation and Ukraine, more than 25\% of all new patients who have not received treatment for TB in the past, have MDR-TB. ${ }^{1}$ Less than one third of notified TB patients worldwide are evaluated with drug susceptibility testing (DST) for RMP; only half of patients with RMP resistance or MDR-TB undergo DST for FQs and second-line injectable drugs. ${ }^{1}$ Only $20 \%$ of MDR-TB cases have access to adequate treatment. ${ }^{3,4}$ It is predicted that the number of patients with MDR-TB and XDR-TB in highburden countries will continue to rise in the coming decades. $^{5}$

Treatment for MDR-TB is challenging for patients, relatives, healthcare providers and health systems. ${ }^{6}$ The level of drug resistance of the causative strain of M. tuberculosis can be highly variable. ${ }^{7}$ Depending on the DST results, current WHO treatment recommendations range from 9 to 20 months of daily combination antibiotic treatment. ${ }^{8}$ The treatment is characterised by a high frequency of adverse drug events, often leading to changes in the regimen. ${ }^{9}$ Due to high costs, some of the second-line drugs are not available in countries where they are needed most. ${ }^{10}$ Despite all of our efforts, according to the latest WHO report, only $55 \%$ of patients with MDR-TB and $34 \%$ of patients with XDR-TB achieve a successful treatment outcome. ${ }^{1}$ Treatment outcomes in MDR-TB and XDR-TB are highly dependent upon available resources. It was recently shown that relapse-free cure-rates in patients with M/XDR-TB can be similar to patients with drug-susceptible TB (DS-TB) when sufficient resources are provided, ${ }^{11}$ and treatment can be personalised. ${ }^{12}$

The aim of the present article is to update previous TBNET (Tuberculosis Network European Trials) recommendations on the optimal management of patients with M/XDR-TB. ${ }^{6}$

\section{MYCOBACTERIUM TUBERCULOSIS DRUG SUSCEPTIBILITY TESTING}

The two main methods to identify the best choice of drugs for individualised treatment are phenotypic DST (pDST; i.e., detecting the growth of an isolate in media containing a specific drug) and genotypic DST (gDST; i.e., detecting established resistance mutations; Table 1). The major advantage of gDST is the short turnaround time to obtain results (Table 2), whereas its main drawback is the limited knowledge of drug resistance mechanisms for some second-line drugs. To date, gDST is not a fully adequate substitute for pDST. For pDST, critical (media-specific) concentrations (Löwenstein-Jensen, Middlebrook 7H10 or BACTEC MGIT ${ }^{\text {тм }} 960^{\text {тм }}$ [BD, Sparks, MD, USA]) are used to separate susceptible from resistant isolates. One of the limitations of critical concentrations is that they treat a continuous variable as though it were binary. Critical concentrations for anti-TB drugs were recently revised for second-line drugs, including bedaquiline (BDQ) and delamanid (DLM). ${ }^{19}$ These phenotypic methods rely on growth of mycobacterial culture in the presence of a single drug concentration. Although this is not yet a WHO-endorsed method, the minimal inhibitory concentrations (MICs) for 12 first- and second-line drugs can be determined with the Sensititre MycoTB microdilution assay (MYCOTB; Trek Diagnostic Systems, Cleveland, OH, USA). ${ }^{38}$

The Xpert ${ }^{\circledR}$ MTB/RIF assay (Cepheid, Sunnyvale, CA, USA) is a frontline gDST, aimed to diagnose TB and detect RMP resistance. ${ }^{39}$ Xpert ${ }^{\circledR}$ MTB/RIF Ultra (Cepheid) was recently shown to have higher sensitivity but slightly lower specificity than Xpert in diagnosing $\mathrm{TB}$, while the performance of the two tests in detecting RMP resistance was similar (sensitivity $98 \%) .{ }^{40}$

DNA sequencing and line-probe assays (LPAs) represent other gDST techniques and are widely used for the detection of resistance to the key drugs-RMP, $\mathrm{INH}$, the FQs, and second-line injectable drugs. LPAs for first-line drugs (GenoType ${ }^{\circledR}$ MTBDRplusV2 [Hain Lifesciences, Nehren, Germany]; Nipro NTM+MDRTB [Nipro, Osaka, Japan] and AID TB Resistance [Aid Diagnostika, Straberg, Germany) and second-line drugs (GenoType ${ }^{\circledR}$ MTBDRsl V2.0 [Nehren] and AID TB Resistance) have been endorsed by the WHO for the detection of drug resistance. ${ }^{14}$

The most promising gDST technology is nextgeneration whole-genome sequencing (WGS), which allows the simultaneous detection of known resistance mutations to all drugs. Emerging reports indicate that WGS can be routinely performed in early positive MGIT (Mycobacteria Growth Indicator Tube) culture and potentially directly from selected clinical samples, ${ }^{32,41}$ predicting drug resistance in high agreement with pDST. Some of the more common genomic mutations can be associated with particular MIC ranges. ${ }^{42,43}$

Xpert and LPAs together currently target the most frequently detected and established drug resistance mutations (Table 1). Treatment regimens that can be designed using results obtained with each molecular test vary greatly. ${ }^{43}$ Regimens that are designed using LPAs and/or Xpert may contain drugs that are not part of the gDST assays and for which pDST show resistance. ${ }^{43}$ WGS can be used as a rule-in test for resistance ${ }^{44,45}$ however, pDST for second-line drugs is still needed to confirm susceptibility and to 


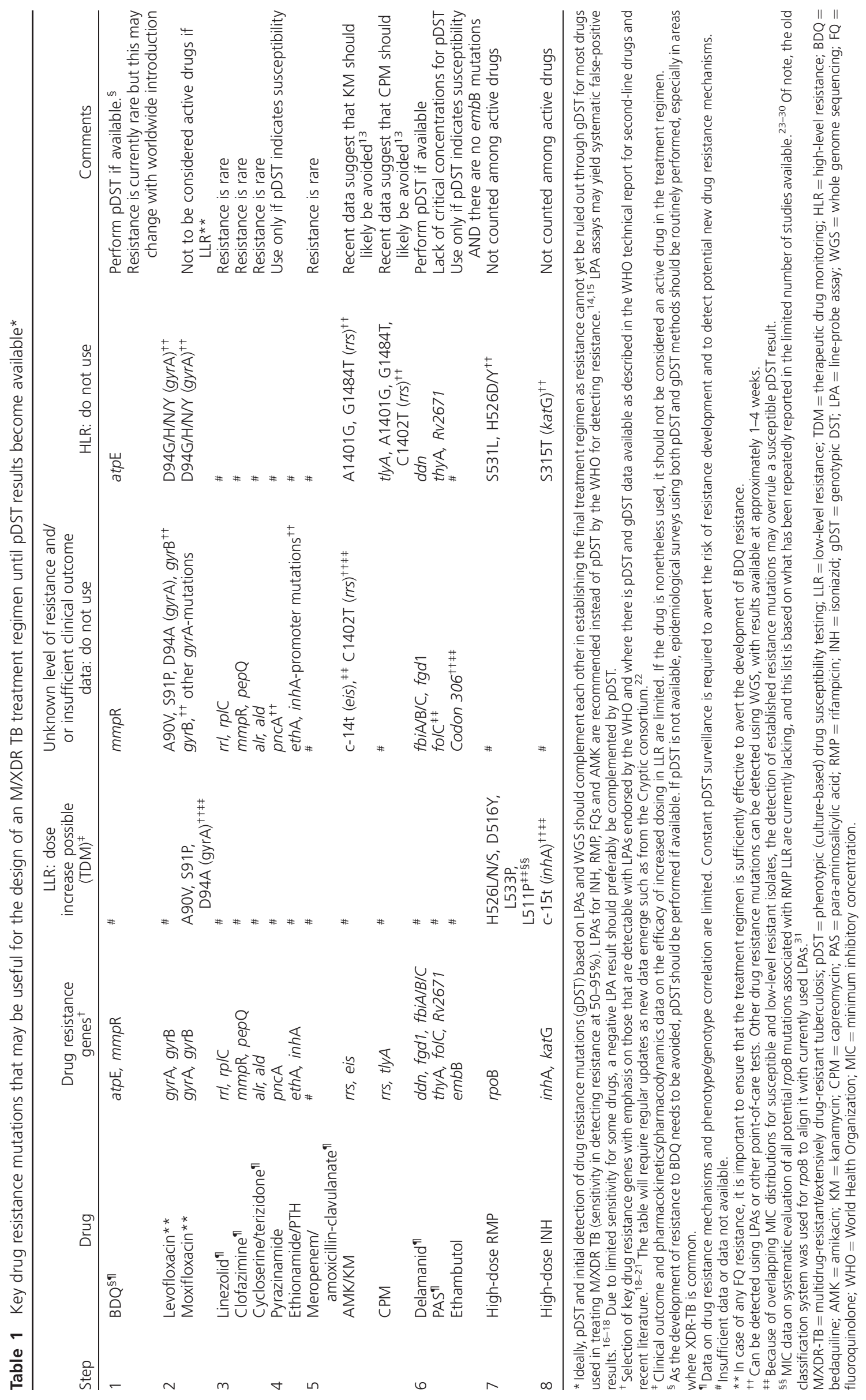


Table 2 TAT for diagnostic procedures from obtaining the initial specimen ${ }^{32-37}$

\begin{tabular}{|c|c|c|}
\hline Diagnostic procedure & Laboratory TAT* & Therapeutic TAT $^{\dagger}$ \\
\hline Smear microscopy & $0.5-1 \mathrm{~h}$ & $6-24 \mathrm{~h}$ \\
\hline GeneXpert ${ }^{\circledR}$ MTB/RIF Ultra & $1.5-2 \mathrm{~h}$ & $6-24 \mathrm{~h}$ \\
\hline Routine PCR (various assays) & $4-8 \mathrm{~h}$ & $24-48 \mathrm{~h}$ \\
\hline LPA (rpoB, inhA, katG, rrs, eis, gyrA, gyrB) & $5-8 \mathrm{~h}$ & $24-48 h^{\neq}$ \\
\hline Drug resistance mutations (sequencing) ${ }^{\$}$ & $2-4$ days ( $+1-8$ weeks of culture) & $1-8$ weeks \\
\hline Culture, MGIT & $1-2$ weeks (smear-positive), $2-6$ weeks (smear-negative) ${ }^{\ddagger}$ & $1-6$ weeks $^{\ddagger}$ \\
\hline DST, MGIT & $1-2$ weeks ( $+1-6$ weeks of culture) & $2-8$ weeks \\
\hline Culture, LJ & 3 weeks (smear-positive), 4-8 weeks (smear-negative) & 3-8 weeks ${ }^{\ddagger}$ \\
\hline DST, LJ (from receipt of sample) & $3-4$ weeks ( $+3-8$ weeks of culture) & $6-12$ weeks \\
\hline MIC determination (7H9 or MGIT) & $1-2$ weeks ( $+1-6$ weeks of culture) & $3-8$ weeks \\
\hline
\end{tabular}

* Time to perform the actual procedure in the laboratory if all resources are available.

${ }^{\dagger}$ The time from taking request of the patient sample to the time the result reaches the prescribing clinician and leads to a treatment decision along with an optimal transport and result reporting chain (TAT in practice is usually much longer and highly dependent on sample transport logistics and mode of delivery of result to the responsible clinician).

${ }^{\ddagger}$ Average time, which varies according to the initial number of bacilli.

§ TAT directly from sputum sample which is an experimental method; time for culture if needed should be added (1-8 weeks depending on method). In the United States, the Centers for Disease Control and Prevention routinely reports sequencing for first-line drugs, second-line injectable drugs, and fluoroquinolones gyrA and gyrB from cultures as well as from direct specimens when possible. In reality, in resource-poor settings the therapeutic TAT may be several days to weeks. TAT = turnaround time; PCR = polymerase chain reaction; LPA = line-probe assay; MGIT = Mycobacteria Growth Indicator Tube; DST = drug susceptibility testing; LJ $=$ Löwenstein-Jensen; MIC $=$ minimal inhibitory concentration.

construct the final optimal drug regimen. ${ }^{21}$ Finally, discordant results between molecular and phenotypic DST are possible, and should be interpreted with caution $^{43,46}$ (Table 1) until there is a better understanding of genotype-phenotype correlations and their clinical importance. ${ }^{12,47}$

\section{DESIGNING A TREATMENT REGIMEN FOR MULTIDRUG-RESISTANT TUBERCULOSIS}

The detection of RMP resistance on a molecular testing assay (e.g., Xpert) is often the first evidence that MDR-TB is present. With rare exceptions, when no other test results confirming RMP resistance are available, no patient should receive a "standardised" MDR-TB regimen based on the results of an Xpert test result alone. The detection of RMP resistance using Xpert should always be confirmed by additional molecular tests that are also capable of detecting mutations that are associated with resistance to other drugs. Prediction of resistance to RMP, INH, FQs and second-line injectable drugs is possible using LPAs at a sensitivity ranging from $75 \%$ to $95 \% .{ }^{14,48-50}$ Resistance against prothionamide (PTH) or ethionamide (ETH) can also be anticipated when a mutation in the promotor region of the inhA gene is detected. The choice of drugs should ideally be based on genotypic prediction of drug resistance using WGS. ${ }^{43}$ However, this is currently possible only at a few centres/countries and cannot be routinely performed directly on sputum specimen, as the amount of $M$. tuberculosis DNA in clinical samples is too low for current WGS protocols. Thus, LPAs are presently the most widely available method used to guide physicians about the initial choice of treatment.

Although classifications of MDR-TB medicines have been proposed by the WHO, ${ }^{8}$ and have recently been revised, ${ }^{51}$ the scientific basis for ranking drugs in groups based on their treatment effect is not yet optimal. Results from a Phase IIb randomised controlled trial showed the benefits of $\mathrm{BDQ}$ in treating of MDR-TB. ${ }^{52}$ Several observational cohort studies have reported 6-month culture conversion rates on BDQ-based treatment regimens of $>90 \%$. This is the best evidence to date for any of the drugs used to treat patients with MDR-TB. Data from a retrospective individual patient data meta-analysis (12030 patients from 25 countries) demonstrated substantial and significant improvements in treatment outcomes with use of BDQ, and also latergeneration FQs, linezolid (LZD), clofazimine (CFZ) and carbapenems. ${ }^{13}$ Pyrazinamide (PZA) also appears to be effective when DST shows susceptibility, while the role of ethambutol (EMB) remains unclear. In this meta-analysis, streptomycin and the secondline injectable AMK had modest benefits, while KM and CPM were associated with worse outcomes. ${ }^{13}$

Based on this evidence, we suggest a stepwise approach for the design of the initial MDR-TB treatment regimen, starting with BDQ combined with later-generation FQs and adding LZD, CFZ and cycloserine (CS)/terizidone (TRD), as appropriate (Table 3). This approach is similar to the recently updated treatment recommendations by the WHO. ${ }^{51}$ However, one important difference is the more detailed step-wise guidance of this current document. The regimen should always be guided by LPAs or WGS, and in the case of genotypic prediction of drug resistance to FQs, the initial combination treatment may additionally include meropenem/amoxicillinclavulanic acid and possibly, also second-line injectable drugs, depending on the results of genotypic testing by LPAs/WGS. Patients receiving injectable drugs should have central venous catheter with subcutaneous access (e.g., port-a-cath) implanted. As M. tuberculosis drug resistance to PZA, EMB and $\mathrm{PTH} / \mathrm{ETH}$ is common in MDR-TB strains (and is not reliably predicted by LPAs), these drugs should not be 
Table 3 Stepwise approach to designing an MDR-TB or XDR-TB treatment regimen*

\begin{tabular}{|c|c|c|}
\hline Step & Drugs & Comments \\
\hline 1 & $\mathrm{BDQ}$ & $\begin{array}{l}\text { Administered for the first } 6 \text { months of treatment. Some experts recommend using the } \\
\text { drug throughout the entire course of treatment }\end{array}$ \\
\hline 2 & LVX or MFX & $\begin{array}{l}\text { No preference for either FQ. Although LVX has less QTc-prolonging potential than MFX, } \\
\text { discontinuation of BDQ in a FQ-containing regimen due to QTc prolongation is } \\
\text { uncommon }\end{array}$ \\
\hline 3 & LZD, CFZ, CS/TRD & $\begin{array}{l}\text { These drugs are likely more potent than Step } 4 \text { drugs and should always be part of the } \\
\text { regimen unless contraindications are present }\end{array}$ \\
\hline 4 & $\mathrm{PZA}^{+}{ }^{+} \mathrm{PTH} / \mathrm{ETH}^{\ddagger}$ & $\begin{array}{l}\text { Add if steps } 1 \text { to } 3 \text { do not lead to five active drugs. These drugs are likely not as potent as } \\
\text { step } 3 \text { drugs. Drug resistance against PZA and/or PTH/ETH should be ruled out }\end{array}$ \\
\hline 5 & MEM/AMX-CLV, AMK & $\begin{array}{l}\text { Add if steps } 1 \text { to } 4 \text { do not lead to five active drugs and in case of FQ resistance. } \\
\text { Administration via a central venous catheter with subcutaneous access (e.g., portacath) } \\
\text { AMX-CLV should be administered simultaneously as MEM } \\
\text { AMK administered for the first } 6-8 \text { months of treatment only. Recent data suggest that } \\
\text { CPM and KM should likely be avoided }{ }^{13}\end{array}$ \\
\hline 6 & DLM, PAS, EMB ${ }^{\dagger}$ & Add if steps 1 to 5 do not lead to five active drugs \\
\hline 7 & $\begin{array}{l}\text { Consider adding } \mathrm{RMPH} \text { if genotypic } \\
\text { testing only shows mutations } \\
\text { associated with low-level } \\
\text { resistance }\end{array}$ & $\begin{array}{l}\text { - } 2 \mathrm{~h} \text { peak levels of } 35 \mathrm{mg} / \mathrm{l} \\
\text { - RMP not to be considered an active drug } \\
\text { - When using RMPH, it is important to remember that RMP decreases exposure } \\
\text { to several other TB drugs, including BDQ and DLM (strong decreases in } \\
\text { exposure, combination is not advised), as well as MFX and LZD (more } \\
\text { modest decreases in exposure, combination is possible with increased doses } \\
\text { and guided by TDM). Co-administration of RMP may also increase the risk of } \\
\text { hepatotoxicity of ETH/PTH }\end{array}$ \\
\hline 8 & $\begin{array}{l}\text { Consider adding } \mathrm{INH}^{\mathrm{H}} \text { if genotypic } \\
\text { testing shows only mutations } \\
\text { associated with low-level } \\
\text { resistance }\end{array}$ & $\begin{array}{l}\text { - } 2 \mathrm{~h} \text { peak levels of } 9-18 \mathrm{mg} / \mathrm{l} \\
\text { - } \mathrm{INH} \text { not to be considered an active drug }\end{array}$ \\
\hline
\end{tabular}

* Pending phenotypic DST, the initial choice of drugs should be guided by more comprehensive molecular DST, not only Xpert ${ }^{\circledR}$ MTB/RIF testing. In general, molecular DST results for INH, RMP, FQs and SLID should be available before a regimen is initiated. The choice of drugs should ideally be guided by molecular-based DST results, which are later complemented with phenotypic DST to confirm susceptibility. Drugs should be added gradually in steps until the regimen consists of at least five effective or likely effective drugs. Close monitoring of adverse events is mandatory for second-line anti-tuberculosis drugs (see Table S1 in Supplementary Data).

${ }^{+}$Depending on the geographic setting, the majority of MDR-TB strains may be PZA- and EMB-resistant. PZA or EMB should not be included in the regimen unless there is proven susceptibility on DST.

${ }^{\ddagger}$ PTH/ETH not to be included in the initial regimen if molecular DST shows a mutation in the promotor of the inhA gene at positions 8,15 or 16 (fabG) MDR-TB = multidrug-resistant tuberculosis; $\mathrm{XDR}-\mathrm{TB}=$ extensively drug-resistant $\mathrm{TB} ; \mathrm{BDQ}=$ bedaquiline; $\mathrm{LVX}=$ levofloxacin; $\mathrm{MFX}=$ moxifloxacin; $\mathrm{FQ}=$ fluoroquinolone; $\mathrm{OTC}=\mathrm{OT}$ interval corrected for heart rate; $\mathrm{LZD}=$ linezolid; $\mathrm{CFZ}=$ clofazimine; $\mathrm{CS}=$ cycloserine; $\mathrm{TRD}=$ terizidone; $\mathrm{PZA}=$ pyrazinamide; $\mathrm{PTH}=$ prothionamide; $\mathrm{ETH}=$ ethionamide; $\mathrm{MEM}=$ meropenem; $\mathrm{AMX}-\mathrm{CLV}=$ amoxicillin-clavulanate; $\mathrm{AMK}=$ amikacin; $\mathrm{CPM}=\mathrm{capreomycin}$; $\mathrm{KM}=\mathrm{kanamycin}$; $\mathrm{DLM}=$

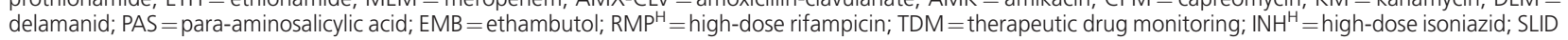
$=$ second-line injectable drugs; DST = drug susceptibility testing.

part of an initial empiric treatment regimen pending the results of pDST. We are very concerned that with the exception of FQs, rapid molecular DST is not available for any other Group A or Group B drug in the novel WHO classification. ${ }^{51}$

Results from genotypic testing using LPA/WGS and pDST should be available at the earliest opportunity in order to design an appropriate personalised regimen. This should then be confirmed by comprehensive pDST in case the initial treatment regimen has to be modified. As long as the results from gDST and pDST allow at least five of these drugs in the regimen (e.g., BDQ, levofloxacin [LVX], LZD, CFZ and CS/ TRD), and there are no perceived adverse events that will likely result in drug withdrawal, the treatment regimen should consist of only orally available drugs (with the exception of FQ- or BDQ-resistant strains). With improved methodology and understanding of genotype-phenotype correlations, discordant susceptibility results will become rarer.

Whenever possible, the treatment regimen should be discussed by a multidisciplinary board (consilium) of experts that may include infectious diseases specialists, pulmonologists, thoracic surgeons, clinical microbiologists and pharmacologists.

\section{DRUG DOSING AND THERAPEUTIC DRUG MONITORING}

Anti-TB drug dosing includes both weight-based, as well as fixed, dosing. Therapeutic drug monitoring (TDM) is used to further individualise dosing based on measured drug concentrations. ${ }^{53,54}$ TDM can help to prevent toxicities associated with high drug concentrations by indicating when lowering the dose is desirable. Treatment failures and acquired drug resistance can be prevented by dose increases when low drug concentrations are found. 55 TDM is indicated in patients with problems associated with drug absorption, distribution, metabolism or excretion, comorbidities such as human immunodeficiency virus (HIV) infection and diabetes mellitus (DM), drug-drug interactions (DDIs), relapsed TB or delayed (or lack of) response even with proven drug susceptibility. ${ }^{56}$ Evidence to support TDM is based on case series, small pharmacokinetic studies and larger 


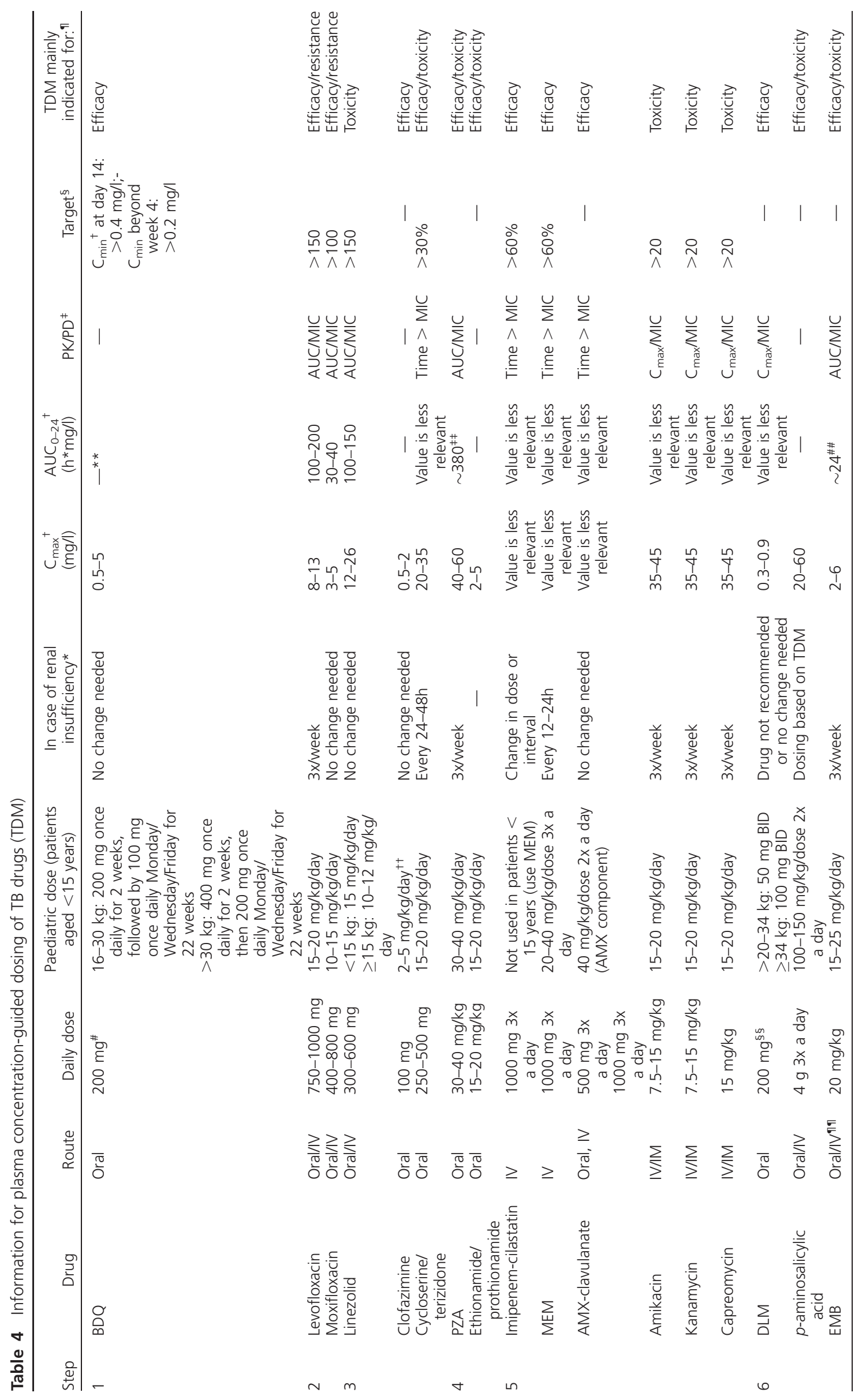




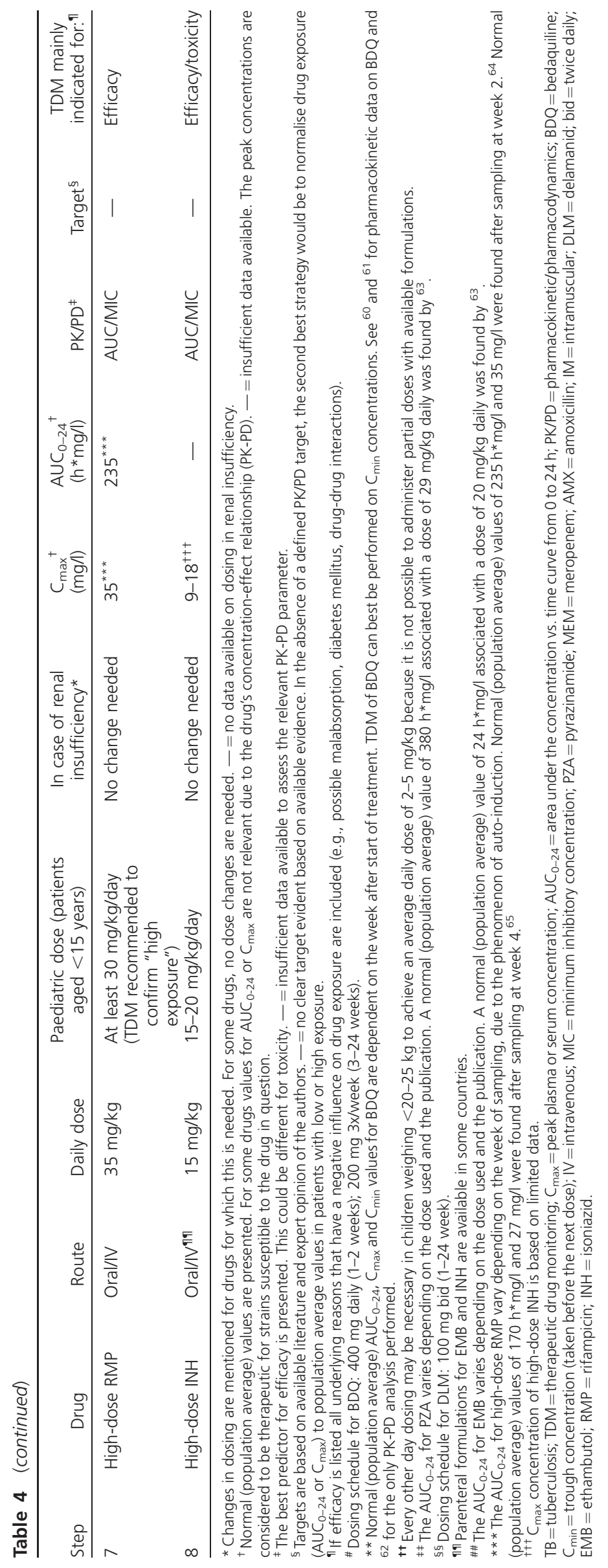


observational cohort studies. Approximately $10 \%$ of acquired drug resistance in patients receiving a standard FQ dose supports the need for TDM-based dose optimisation of these drugs. Hollow-fibre infection models and animal studies showed a clear correlation between drug exposure and effect, allowing researchers to assess which pharmacokinetic index (parameter) is relevant for each drug, i.e., protein-free total exposure (area under the empirical free-response receiver operating characteristic curve [fAUC]), peak concentrations (free maximum concentration $\left[f \mathrm{C}_{\max }\right]$ ) or time above $\mathrm{MIC}$ (with trough concentration or free minimum concentration as relevant parameter). If clinically validated pharmacokinetic/pharmacodynamics targets are not available, population ('normal') pharmacokinetic measures are used as best-case scenario target values. ${ }^{53,57}$ To enable pharmacokinetic/pharmacodynamic based dose optimisation, a limited sampling strategy using at least two time points can be utilised. ${ }^{57}$ This method yields a better estimate of drug clearance and total exposure (AUC) than traditional sample collection. The latter includes sampling at $2 \mathrm{~h}$ and $6 \mathrm{~h}$ after observed drug intake in a fasting state. ${ }^{53,54}$ This was designed to provide information about absorption and approximate the peak concentration $\left(\mathrm{C}_{\max }\right)$. Both approaches can be completed within a single nursing shift, or in an outpatient clinic. Because of sample stability and patient friendliness, dried blood spot (DBS) or saliva sampling were explored as potential alternatives for plasma samples. ${ }^{58}$ Many single and multi-component assays using liquid chromatography have been published to support TDM. Mass spectrometry is preferred over other detection techniques due to the specificity and sensitivity needed for DBS, easier sample preparation and short runtimes. However, cheaper conventional HPLC-UV (high-performance liquid chromatography-ultraviolet) methods can be used in less well-resourced settings, as anti-TB drug concentrations are in the range of $\mathrm{mg} / \mathrm{l}$. External quality control of the assays is of great importance in maintaining high-quality analytical services. ${ }^{59}$ In Table 4, an update is provided on the targets for TDM of WHO-recommended drugs. ${ }^{6}$ TDM is currently performed in specialised centres for some of the second-line drugs such as FQs, aminoglycosides, LZD and CS, in addition to the first-line drugs. Some laboratories also offer assays for less frequently measured drugs such as BDQ, CFZ and para-aminosalicylic acid (PAS). TDM frequency depends on the complexity of the situation, but in general, if TDM is indicated, an initial assessment of drug concentrations, followed by a confirmatory measurement, is considered sufficient if the concentration is within the therapeutic range. To be of use to clinicians, the TDM service should provide an interpretation of the results, and not only raw drug concentrations. Moreover, to achieve wider use of TDM, it will be necessary to ensure it is both more convenient and less costly.

\section{ADVERSE EVENTS}

Second-line anti-TB drugs are often associated with adverse events, ranging from mild to life-threatening, which require temporary or permanent drug discontinuation. ${ }^{66}$ Rapid evaluation, diagnosis and management of adverse events are extremely important as these can compromise treatment efficacy, leading to treatment failure and a higher rate of mortality.

Most adverse events are easily recognised and usually reported by patients in time. It is, however, important to check regularly for symptoms and to perform laboratory screenings of adverse events. One of the benefits of directly observed therapy (DOT) is the ability to monitor patients daily for symptoms. Laboratory screening can detect adverse events often not detected by the patient or DOT provider. Important baseline and routine monitoring tests for patients on second-line anti-TB drugs include a pregnancy test (many clinicians check pregnancy tests monthly in women of childbearing age on MDR-TB treatment), HIV testing, serum creatinine and serum potassium (baseline and monthly while receiving an injectable drug), thyroid stimulating hormone (every 3 months if receiving ETH/PTH or PAS), liver serum enzymes (monthly monitoring for all patients at risk; more often during the first month for patients with viral hepatitis), haemoglobin and white blood count (monthly; more frequently at first if receiving LZD), clinical assessment for peripheral neuropathy/vibration perception (baseline and monthly while receiving LZD), audiometry (baseline and monthly during treatment with injectable drug), vision tests (baseline, monthly, and in case of clinical suspicion of toxicity for patients on EMB or LZD), electrocardiogram (for patients receiving QTc interval-prolonging drugs, such as BDQ, CFZ, moxifloxacin and/or DLM, at baseline, weeks 2, 12 and 24).6,67,68

Up to $90 \%$ of patients experience regimen changes during the course of treatment (irrespective of the regular discontinuation of treatment with injectable drugs). ${ }^{9}$ Complete discontinuation of the entire regimen because of adverse events is rare, but discontinuation of one or more drugs and substitution by other drugs due to adverse events is common. In some cases (e.g., polyneuropathy or myelosuppression due to LZD; severe depression/suicidal ideation due to CS; ototoxicity due to aminoglycosides), the causative drugs must be discontinued and should not be reintroduced (Table S1 in Supplementary Data). Pyridoxine $(50 \mathrm{mg}$ for every $250 \mathrm{mg}$ of CS/TRD and $50 \mathrm{mg}$ for $600 \mathrm{mg}$ of LZD) is recommended by some experts to be routinely provided to all patients with CS/TRD and LZD to reduce the risk of neurological adverse events. 
Social and psychological support for these patients should not be neglected. Patients should be continuously motivated to adhere to treatment and providers have an important role here. Table S1 (in Supplementary Data) summarises the most frequent adverse events, the likely responsible drugs and strategies to manage them.

\section{SPECIAL CONSIDERATIONS FOR TREATMENT IN CHILDREN}

Due to poor case detection, only $3-4 \%$ of the estimated 25000-32000 children who develop MDR-TB annually receive treatment. ${ }^{69}$ Household contact tracing has the potential to identify 12 times as many children with MDR-TB, ${ }^{69}$ and the burden of MDR-TB could be further reduced by contact tracing coupled with preventive therapy. ${ }^{70}$

When MDR-TB is suspected in a child, it is imperative to attempt bacteriological confirmation, with induced sputum (or gastric aspirate in children unable to expectorate). However, most cases are diagnosed clinically, in which case DST of $M$. tuberculosis from the presumptive source case is used to guide treatment regimens. Treatment responses are usually ascertained by clinical assessments. Individualised DST-guided (source case or patient) treatment is preferred over standard treatment regimens.

An individual patient meta-analysis reported that $14 \%(119 / 842)$ of children treated for MDR-TB received injectable-sparing regimens that resulted in successful outcomes for $72 \%(41 / 57)$ of children with confirmed MDR-TB and 94\% (58/62) of children with probable MDR-TB. ${ }^{68}$ This evidence, predating new more potent oral medication, informed the WHO recommendation to exclude injectables from regimens for children with mild disease. ${ }^{68}$

There is emerging evidence of the effectiveness of treating children with new (BDQ and DLM) and repurposed (LZD and CFZ) medications, ${ }^{71}$ and providers should strive to treat all children, including those with confirmed MDR-TB, with effective injectable-free regimens, as outlined in Table 3 and in recent WHO guidance. ${ }^{51}$ Individualised DSTguided treatment is preferred over standard treatment regimens, irrespective of the duration of DST-guided treatment. For children, treatment with second-line injectable drugs is particularly traumatic when administered in daily intramuscular injections, as this can result in hearing loss in approximately $25 \%$ of children, ${ }^{72}$ and should not be administered in the absence of age-appropriate audiologic monitoring. While dependent on the treatment setting and clinical scenario, a risk-benefit analysis in children will most often favour completion of a MDR-TB regimen with DLM, PAS and/or EMB (Step 6), as opposed to Step 5 in Table 3.

Children should remain with their parent or caregiver during MDR-TB treatment. Decisions regarding hospitalisation depend on the setting, clinical status, treatment regimen and ability of the care team to monitor medication administration in the community. Most children with MDR-TB currently receive fractionated adult tablets that are crushed and administered in a syringe with liquid, or on a spoon with soft food. However, children with MDR-TB should soon have access to dispersible formulations $^{73}$ that promise to simplify treatment and improve efficacy. These new formulations, coupled with expected data on efficacy, safety and pharmacokinetics of new drugs in younger children, ${ }^{74}$ offer hope that treatment for children will be less toxic, more tolerable and increasingly efficacious in the near future.

\section{SPECIAL CONSIDERATIONS FOR MDR-TB TREATMENT IN RESOURCE-LIMITED SETTINGS}

While all the principles addressed in this article should apply to all patients affected by M/XDR-TB, the reality in resource-poor settings is that access to new diagnostic technologies, newer drugs, and programmatic capacity is limited. Indeed, the frontline test for RMP resistance, Xpert ${ }^{\circledR}$ MTB/RIF Ultra (previously Xpert MTB/RIF version 4; Cepheid), is only available in a limited number of high-burden countries, ${ }^{75}$ and even then is only accessible to a limited segment of the TB population. Furthermore, less than $50 \%$ of those treated for TB in high-burden countries have microbiological proof of disease (not only due to the lack of diagnostic access, but also because of reduced sensitivity in some population groups), second-line DST is only accessible to $\sim 30 \%$ of patients with MDR-TB, $\sim 20 \%$ of MDR-TB patients have access to treatment and access to newer drugs such as BDQ and DLM is very limited. In India, for example, which has the highest drug-resistant TB (DR-TB) burden worldwide, BDQ access for MDRand XDR-TB remains very limited. ${ }^{75,76}$ With the extremely high DR-TB burden, treatment often occurs in a decentralised setting. ${ }^{76}$ There is also a lack of experienced and appropriately trained staff, and most MDR-TB patients are treated by junior medical officers in district general hospitals and in clinics. Access to specialist expertise (pulmonologists and infectious disease physicians) is extremely limited, and there is hardly any access to thoracic surgery or insertion of central venous catheters for the administration of intravenous drugs.

Nevertheless, important progress has been made in recent years and more can be achieved with investment in technology and resources. For example, Xpert is now the first-line TB test for all patients with suspected TB in South Africa, the country with the highest number of patients with MDR-TB on the African continent. Drawbacks include the lack of 
simultaneous testing for INH resistance, resulting in an increased risk of the development of RMP resistance on a standard treatment regimen when INH resistance is present but not recognised or taken into account $(15 \%$ of isolates with INH-monoresistant TB are not detected and RMP monotherapy effectively occurs in the continuation phase), ${ }^{77}$ and there is controversy over how trace-positive Xpert Ultra results are interpreted. ${ }^{40}$ High-burden countries have also made huge strides in upgrading their diagnostic infrastructure. In some high-burden countries, such as South Africa, Xpert-positive, RMPresistant samples are automatically tested using firstand second-line pDST, and extended sequencing and/ or first- and second-line LPAs directly on sputum to speed up the diagnosis of MDR and XDR-TB. ${ }^{78}$

While access to drugs and diagnostics remains a challenge, the landscape is rapidly changing. The WHO recently recommended a shorter, 9-11 month course regimen based on observational data. ${ }^{68,79}$ The preliminary results of the STREAM I study showed that it was not non-inferior to the conventional 21 to 24-month regimen. ${ }^{80}$ Nevertheless, the trial demonstrated that under research conditions using LPAs for patient selection, high cure rates of MDR-TB ( $~ 80 \%)$ could be achieved. ${ }^{80}$ The results highlight the shortcomings of programmatic and capacity development that need to be addressed in endemic countries. Although adopted by several countries, this regimen has several drawbacks, as it is inappropriate in endemic countries with high rates of background resistance to first-line drugs, toxicity etc.

As already outlined above, several lines of evidence support the inclusion of BDQ as a frontline drug for the treatment of MDR-TB if access to genotypic analysis is secured to evaluate FQ resistance. The WHO now supports the use of BDQ as a frontline drug as part of a MDR-TB regimen following recent evidence of its efficacy in the treatment of MDR-TB. ${ }^{51,81}$ There are concerns about the emergence of BDQ resistance if LPA results are delayed or unless $B D Q$ is used in combination with a sufficient number of other drugs with proven action using DST. ${ }^{82}$

While the inclusion of BDQ in an MDR-TB regimen is encouraging, even better regimens are required for the treatment of XDR-TB. For example, in a recent prospective study, approximately one third of XDR-TB patients still had unfavourable outcomes despite using a BDQ and LZD-based regimen. ${ }^{83}$ Approximately $10 \%$ of XDR-TB patients are surviving as treatment failures; thus programmatically incurable TB remains a clinical problem despite the advent of newer drugs, ${ }^{76}$ and poses major ethical and management challenges for clinicians in endemic settings. ${ }^{76}$ A major unmet need remains the lack of community-based long-stay and palliative care facilities in endemic settings. ${ }^{84}$

\section{MANAGEMENT OF COMORBIDITIES: HIV, DIABETES MELLITUS AND COPD}

Compared with people without HIV co-infection, people living with HIV (PLHIV) are at significantly higher risk of primary MDR-TB (pooled odds ratio $2.28,95 \%$ confidence interval $[\mathrm{CI}] 1.52-3.04)$ but not secondary MDR-TB. ${ }^{85}$ PLHIV with MDR-TB also have lower rates of relapse-free cure than HIVnegative MDR-TB patients $(24.0 \%$ v. $59.4 \%, P<$ $0.001) .{ }^{86}$

Overlapping toxicity, especially nephro- and hepatotoxicity, and DDIs require close monitoring. Possible DDI exist between BDQ and several antiretroviral therapy (ART) regimens, especially those containing efavirenz and/or lopinavir/ritonavir. ${ }^{87-89}$ Often, but not exclusively, DDIs are mediated via the cytochrome P450 3A4 system. Updated information on DDIs, including those for second-line TB drugs, can be found at https://www.hivdruginteractions.org/ or at https://aidsinfo.nih.gov/ guidelines/html/4/adult-and-adolescentopportunistic-infection/325/tb. ART-naïve PLHIV with newly diagnosed TB should generally be started on antiretrovirals within the first 2 weeks, with the possible exception of TB meningitis. ${ }^{90}$ Some physicians suggest a wait of up to 8 weeks in patients with CD4 counts $>50-100$ cells $\left./ \mathrm{mm}^{3}\right)$. Steroids can be used for the prevention (CD4 counts $<50$ cells $/ \mathrm{mm}^{3}$ ) and treatment of immune reconstitution inflammatory syndrome (IRIS). ${ }^{91}$ These general recommendations can probably be extrapolated to PLHIV with MDR-TB, although specific evidence is lacking, and it is a clinical challenge to differentiate between IRIS and lack of treatment response in MDR-TB patients.

DM, especially when poorly controlled, increases the risk of M. tuberculosis infection and TB disease, as well as the risk of drug resistance, treatment failure and recurrent disease. ${ }^{92}$ Optimal DM management, aimed at reversing these risks and improving patient outcome, consists of proper glycaemic control and measures to reduce the risk of cardiovascular disease. Glucose control should be managed using metformin or insulin, which lack clinically significant DDI with RMP. Metformin may be associated with decreased mortality during TB treatment, suggesting a potential role for this agent as adjunctive, host-directed therapy. ${ }^{93}$ Cardiovascular disease may explain high rates of early mortality in DM-TB patients, ${ }^{94}$ and cardiovascular risk assessment should be considered to guide management in terms of counselling and prescription of anti-hypertensive, lipid-lowering and anti-platelet treatment. Studies are needed to determine whether prolonged or intensified TB treatment may also improve outcomes for DM-TB patients. ${ }^{95}$

There is a shared relationship between TB and risk of chronic obstructive pulmonary disease (COPD), with cigarette smoking, smoke from open stoves used 
for cooking or heating and inhaled steroid use as the most important risk factors. The association with MDR-TB is less clear. As TB causes airway obstruction and restriction, and MDR-TB is more frequent in retreatment cases, COPD is more prevalent in MDRTB cases. In China, previous TB was the strongest predictor for MDR-TB in COPD patients. ${ }^{96}$ The use of FQs for COPD exacerbations increases the risk of drug resistance. Inhaled steroids increase the risk of TB but are recommended, particularly for patients with GOLD (Global initiative for chronic Obstructive Lung Disease) stage IV COPD. The risk-benefit ratio for their use in advanced COPD GOLD stage III/ IV and TB remains unclear. ${ }^{97}$

\section{SMOKING CESSATION}

Tobacco smoking adversely affects outcomes in patients with $\mathrm{TB},{ }^{98}$ and has been identified as a risk factor for DR-TB. Smoking impairs pulmonary immunity, rendering patients more susceptible to active $\mathrm{TB} ;{ }^{99}$ it also reduces the rate of culture conversion and doubles the risk of mortality. ${ }^{100}$ Active cigarette smoking patients with MDR-TB have delayed time to culture conversion when compared to non-smoking patients with MDR-TB, or patients with non-MDR-TB. ${ }^{101}$ There are few trials and a lack of good-quality evidence with regard to smoking cessation interventions for patients with DS-TB or DR-TB. ${ }^{102}$ A recent Cochrane review of smoking cessation interventions failed to identify any trials that met the pre-set inclusion criteria. ${ }^{103} \mathrm{~A}$ randomised trial carried out in South Africa showed that motivational interviewing by lay counsellors to promote smoking cessation in TB patients approximately doubled sustained smoking abstinence for at least 6 months compared with brief advice alone, but made no comment on disease outcomes. ${ }^{104}$

\section{PHYSIOTHERAPY, REHABILITATION AND PALLIATIVE CARE}

As with DS-TB patients, patients with MDR-TB often develop chronic combined restrictive-obstructive ventilation disorders with reduced exercise capacity, exertion dyspnoea, increase bronchial secretions and musculoskeletal pain causing disability in everyday life activities. ${ }^{105}$ The aims of respiratory physiotherapeutic interventions are to improve physiological fitness, exercise tolerance and quality of life. Patients undergoing thoracic surgery benefit from pre- and post-surgical physiotherapy. Each patient should receive a respiratory physiotherapy programme starting as early as possible in the in-patient phase of treatment and tailored to the individual physical abilities. Implementation of physiotherapy requires trained staff, therapy rooms and adequate equipment. ${ }^{106,107}$
All patients with MDR-TB at risk of, or with TBassociated sequelae should benefit from rehabilitation as early as their clinical condition allows them to accomplish the rehabilitation programme. Pulmonary rehabilitation starts with a detailed assessment, followed by patient-tailored therapies. These include, but are not limited to, continuing exercise training, education and behaviour changes, and are designed to improve the physical and psychological condition and promote the long-term adherence of health-enhancing behaviours. ${ }^{108}$ General principles of exercise training, including a combination of exercise and endurance training, are recommended. In addition to pulmonary rehabilitation, other programmes could be required for patients with extra-pulmonary disease.

Palliative care should be a part of any MDR-TB management with the aim of relieving the suffering of patients during treatment, and especially when all possibilities to achieve a cure have failed. ${ }^{109}$ Palliative care should be integrated into an existing TB programme and, depending on available resources, can vary from in-patient to home-based models and hospices. It consists of a multidisciplinary approach for symptom control, and includes proper infection control measures. It is absolutely essential that professionals caring for MDR-TB patients are knowledgeable regarding the principles of basic palliative care and symptom-oriented management. ${ }^{6}$

\section{ROLE OF SURGERY IN THE MANAGEMENT OF PATIENTS WITH MULTIDRUG-RESISTANT TUBERCULOSIS}

Expert opinion about the conditions for and timing of surgery in MDR-TB, the types of operation, and preoperative and postoperative management have been summarised in a WHO consensus statement published in 2014. ${ }^{110}$ The main goals of surgery are to eliminate life-threatening complications, to remove the source of infection and to improve the chances of a medical treatment being effective. To ensure best possible treatment outcomes, the indications for surgery should be discussed in a multidisciplinary consilium, ${ }^{6}$ and pulmonary surgery in patients with MDR-TB should only be performed at experienced centres. ${ }^{111}$ The optimal time-point for elective surgery is the time of culture conversion on adequate anti-TB chemotherapy. It should be earlier in emergency situations, such as in case of recurrent haemoptysis, profuse lung haemorrhage or tension pneumothorax, or when culture conversion does not occur within 6-9 months on DST-guided individualised medical therapy. Under optimal conditions and in selected patients, treatment success rates of combined medical and surgical treatment of patients with MDR-TB can approach $90 \%$.

The best outcomes are achieved for localised 
disease and with unilateral lobectomies. ${ }^{112}$ Contraindications to surgery include bilateral cavitary disease (subtotal affected lungs), poor cardiorespiratory function, severe comorbidity and active bronchial TB. HIV infection is not a contraindication to surgery, but PLHIV should preferably have undetectable viral replication on ART. Preoperative assessment should include bacteriological examination of the sputum, contrasted thoracic computed tomography, bronchoscopy and cardiopulmonary function testing by body plethysmography, spiro-ergometry, 6minute walk test and echocardiography. Perfusion lung scintigraphy should be performed before pneumonectomy if the patient has borderline pulmonary function or bilateral disease.

The most common surgical procedures are anatomical pulmonary resections and pneumonectomies. Thoracoplasty is necessary when resection surgery is contraindicated. Pre-operative physical exercise and post-operative rehabilitation (including psychological support) are known to improve treatment outcomes. Minimally invasive surgery, especially using a robotic approach, is associated with a shorter duration of inhospital stay, less operating injury and less pain. ${ }^{113}$

\section{DURATION OF TREATMENT}

The evidence base for recommendations for the duration of medical MDR-TB treatment is not as well-established as for DS-TB. The duration of MDRTB treatment varies depending on the extent of the disease, the extent of bacillary drug resistance and the availability of drugs likely to be effective in a MDRTB regimen.

Treatment duration is currently recommended to be at least 20 months. ${ }^{8}$ However, the duration may be modified according to a patient's response to treatment and to the clinical, radiological and bacteriological evolution. These recommendations are consistent with an individual patient data metaanalysis (7832 analysed patient data), which defined the optimal duration of treatment to be 19-22 months (mean 21 months). ${ }^{13}$ An alternative, shorter regimen has recently been recommended for patients with specific eligibility criteria. ${ }^{8}$ This standardised regimen includes seven drugs for 4-6 months (intensive phase), followed by four drugs for a 5-month continuation phase. The use of this shorter regimen is supported by one prospective randomised phase III study showing high success rates in settings with low levels of drug resistance. ${ }^{114}$ Nevertheless, the applicability of this shorter regimen according to the current WHO eligibility criteria appears to be limited, especially in regions with higher rates of drug resistance, such as in Europe. ${ }^{115}$ Individualised therapy is a more suitable approach. Multiple on going and planned trials are investigating the possibility of shortening treatment regimens using new/re-purposed drugs (reviewed in detail in Dheda et al). ${ }^{76}$ The results of these trials will probably shape M/XDR-TB treatment in the coming years.

While the WHO currently recommends the use of BDQ only for the first 6 months of an M/XDR-TB regimen, prolonged $\mathrm{BDQ}$ treatment appears to be well tolerated. ${ }^{116}$

Biomarkers indicating the optimal duration of therapy (including cessation time-point) would be a highly desirable tool for clinicians. Markers such as 6month culture conversion status have been strongly associated with end-of-treatment outcomes. Several technologies and biomarkers are under investigation to predict treatment duration. To date, however, no biomarkers that can be used to individualise the duration of treatment have been introduced into routine clinical practice. ${ }^{117}$

\section{TREATMENT OUTCOMES}

Standardised treatment outcomes for MDR-TB were first published in 2005, and the classification 'cure' at the time needed five negative sputum cultures during the continuation phase of treatment. ${ }^{118}$ This number was reduced to three in the 2013 revision of the TB reporting framework. ${ }^{119}$ Obtaining sputum specimens during successful treatment has proven to be difficult, leading to a marked under-reporting of formal cure. Furthermore, the complex clinical course of TB call into question the validity of defining cure at the end of treatment, as underlined by the chance of relapse in treatment efficacy trials. ${ }^{120,121}$

New treatment outcome definitions based on sputum culture status after 6 months of treatment and an observation period of 1 year after the termination of MDR-TB treatment have been proposed (Table S1 in Supplementary Data). ${ }^{122,123}$ Because most relapses occur within the first year after treatment completion, these new 'simplified' treatment outcome definitions have an advantage when defining 'cure' following MDR-TB treatment compared to the current WHO definitions. MDR-TB treatment failures are also better identified using these simplified definitions. Although in many settings, it is difficult to follow MDR-TB patients for 1 year after the end of treatment, ${ }^{124}$ TB programmes should aim for this goal to achieve the targets of the End TB Strategy. 'Simplified outcome definitions' are identical for MDR-TB and DS-TB. They can be used irrespective of resistance status and duration of treatment, and have already been applied in different settings (Table 5). ${ }^{11,125,126}$

\section{MANAGEMENT OF MDR-TB CONTACTS}

Preventive therapy for MDR-TB, coupled with contact tracing could further reduce the burden of 
Table 5 Outcome definitions of MDR-TB treatment according to WHO ${ }^{119}$ and TBNET ${ }^{122}$

\begin{tabular}{|c|c|c|}
\hline & WHO definitions & Simplified definitions (TBNET) \\
\hline Cured & $\begin{array}{l}\text { Treatment completed as recommended by the } \\
\text { national policy without evidence of failure AND } \\
\geq 3 \text { consecutive cultures taken at least } 30 \text { days } \\
\text { apart are negative after the intensive phase }\end{array}$ & $\begin{array}{l}\text { A negative culture status } 6 \text { months after } \\
\text { treatment initiation, no positive cultures } \\
\text { thereafter, and no relapses within } 1 \text { year after } \\
\text { treatment completion }\end{array}$ \\
\hline Treatment completed & $\begin{array}{l}\text { Treatment completed as recommended by the } \\
\text { national policy without evidence of failure BUT } \\
\text { no record that } \geq 3 \text { consecutive cultures taken at } \\
\text { least } 30 \text { days apart are negative after the } \\
\text { intensive phase }\end{array}$ & NA \\
\hline Treatment failed & $\begin{array}{l}\text { Treatment terminated or need for permanent } \\
\text { regimen change of at least two TB drugs } \\
\text { because of: } \\
\text { - lack of conversion by the end of the } \\
\text { intensive phase, or } \\
\text { - bacteriological reversion in the } \\
\text { continuation phase after conversion to } \\
\text { negative, or } \\
\text { - evidence of additional acquired } \\
\text { resistance to fluoroquinolones or } \\
\text { second-line injectable drugs, or } \\
\text { - adverse drug reactions }\end{array}$ & $\begin{array}{l}\text { A positive culture status } 6 \text { month after treatment } \\
\text { initiation or thereafter, or a relapse within } 1 \\
\text { year after treatment completion }\end{array}$ \\
\hline Died & $\begin{array}{l}\text { A patient who dies for any reason during the } \\
\text { course of treatment }\end{array}$ & $\begin{array}{l}\text { A patient who dies for any reason during the } \\
\text { course of observation }\end{array}$ \\
\hline Lost to follow-up & $\begin{array}{l}\text { A patient whose treatment was interrupted for } \\
\geq 2 \text { consecutive months }\end{array}$ & $\begin{array}{l}\text { Non-receipt of care } 6 \text { months after treatment } \\
\text { initiation }\end{array}$ \\
\hline Not evaluated & $\begin{array}{l}\text { A patient for whom no treatment outcome is } \\
\text { assigned (this includes cases "transferred out" } \\
\text { to another treatment unit and whose } \\
\text { treatment outcome is unknown) }\end{array}$ & NA \\
\hline Undeclared & NA & $\begin{array}{l}\text { - No culture status at } 6 \text { months while the } \\
\text { patient was receiving care, or } \\
\text { - No post-treatment assessment }\end{array}$ \\
\hline Treatment success & The sum of cured and treatment completed & 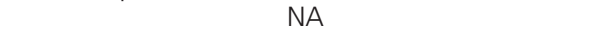 \\
\hline
\end{tabular}

MDR-TB = multidrug-resistant TB; WHO = World Health Organization; TBNET = Tuberculosis Network European Trials; NA = not applicable; TB = tuberculosis.

MDR-TB, and is now endorsed by the WHO in highrisk household contacts. ${ }^{70}$ In the absence of active TB, latent infection with M. tuberculosis (LTBI) is diagnosis based on a positive tuberculin skin test or interferon- $\gamma$ release assay result. ${ }^{127}$ Before considering preventive chemotherapy for MDR-TB contacts with LTBI, TB disease should first be excluded using imaging studies and microbiological or molecular methods. In the majority of the cases, drug resistance patterns in the index patient and the contact with active TB are concordant. ${ }^{128}$

Reliable data on the choice of drugs and the duration of preventive chemotherapy in contacts of patients with MDR-TB are limited. A recent systematic review and meta-analysis found an estimated MDR-TB incidence reduction of $90 \%$ using data from five comparison studies. If the index case is FQsusceptible, an FQ-based preventive treatment regimen of 6 months' duration, with or without an additional drug to which the index strain is susceptible has been recommended. ${ }^{129}$ Cost-effectiveness appears to be high when an FQ/EMB combination regimen is used. ${ }^{129}$ The preventive treatment regimen for children should also include LVX or moxifloxacin. This approach is supported by recent evidence demonstrating the safety of long-term exposure to LVX, further shifting the balance of benefits vs. risks. ${ }^{130}$ As new, dispersible FQ formulations for children have been developed, preventive treatment can also be given to this high-risk group. There are currently no recommendations for preventive chemotherapy when the index case is FQ-resistant but otherwise drug-susceptible.

\section{CONCLUSIONS}

DR-TB remains a major global public health concern, subverting gains made in TB control, and forms a major component of the future cost and mortality projections for antimicrobial resistance. Although the availability of newer drugs and diagnostic tools is encouraging, at least two major challenges remain. First, the issue of capacity development, training, and access to newer drugs and diagnostic technologies by endemic countries needs to be urgently addressed. It is indeed alarming that only $\sim 20 \%$ of patients can currently access MDR-TB treatment. Second, and in parallel, factors such as the determination of optimal dosing and drug delivery approaches, ${ }^{131}$ affordable therapeutic drug monitoring, and improved provision of adherence and psychosocial support will need to be addressed, or the newer drugs will be rapidly lost to further drug resistance. Other important aspects that need to be optimised are the duration of treatment, 
treatment of DR-TB in children and in close contacts, and roll-out of compatible ART regimens. With the advent of injection-free regimens, and the importance of BDQ, FQs and LZD as the backbone of MDR-TB treatment, the definition of XDR-TB should probably be revised by including these drugs and excluding second-line injectable drugs. ${ }^{132}$

The two 'elephants in the room' that remain are the lack of strategies and models for community-based active case finding and the provision of DST-guided, tailor-made treatment regimens to individual patients. The bulk of DR-TB transmission occurs from undiagnosed cases disproportionately living under poor housing conditions, including informal settlements in TB-endemic countries. However, community-based active case finding using newer molecular tools is feasible and will need to be urgently addressed and scaled up. ${ }^{133}$ Treating patients with individual DST-guided treatment regimens will likely have a major impact on the development of drug resistance, which naturally occurs in all treatment programmes using programmatic 'one-size-fits-all' standardised treatment approaches (Figure S1 in Supplementary Data). ${ }^{12}$ Policy makers and treating physicians should not compromise on extended and repeated DST to guide optimal and personalised management of patients with MDR- and XDR-TB.

Prevention of DR-TB remains a major priority. At present there is no vaccine that effectively prevents TB in individuals exposed to M. tuberculosis. In addition to the specific strategies already mentioned, prevention will best be achieved by effective treatment and by addressing key drivers of TB, including poverty and overcrowding, malnutrition, HIV coinfection, tobacco smoking and DM, among others. ${ }^{134}$ However, this will require significant and sustained global investment and political will.

\section{Acknowledgements}

This management guidance is endorsed by the TBNET. The authors are grateful for critical reading and helpful comments from members of the RESIST-TB steering committee.

$\mathrm{JH}$ and CL are supported by the German Center for Infection Research (DZIF). TS is supported by The Swedish Heart and Lung Foundation and the Swedish Research Council. KD is supported by the South African Medical Research Council and the European Union (EDCTP)

\section{References}

1 World Health Organization. Global tuberculosis report, 2018. WHO/CDS/TB/2018.20. Geneva, Switzerland: WHO, 2018.

2 World Health Organization. The WHO End TB Strategy. Geneva, Switzerland: WHO, 2015.

3 Falzon D, Jaramillo E, Wares F, Zignol M, Floyd K, Raviglione M C. Universal access to care for multidrug-resistant tuberculosis: an analysis of surveillance data. Lancet Infect Dis 2013: 13: 690-697.

4 Nourzad S, Jenkins H E, Milstein M, Mitnick C D. Estimating the global burden of multidrug-resistant tuberculosis among prevalent cases of tuberculosis. Int J Tuberc Lung Dis 2017: 21: 6-11.

5 Sharma A, Hill A, Kurbatova E, et al. Estimating the future burden of multidrug-resistant and extensively drug-resistant tuberculosis in India, the Philippines, Russia, and South Africa: a mathematical modelling study. Lancet Infect Dis 2017: 17: 707-715.

6 Lange C, Abubakar I, Alffenaar J W, et al. Management of patients with multidrug-resistant/extensively drug-resistant tuberculosis in Europe: a TBNET consensus statement. Eur Respir J 2014: 44: 23-63.

7 Günther G, van Leth F, Alexandru S, et al. Multidrug-resistant tuberculosis in Europe, 2010-2011. Emerg Infect Dis 2015: 21: 409-416.

8 World Health Organization. Guidelines for the programmatic management of drug-resistant tuberculosis, 2016 update. WHO/HTM/TB/2006.361. Geneva, Switzerland: WHO, 2016.

9 Günther G, van Leth F, Alexandru S, et al. Clinical management of multidrug-resistant tuberculosis in 16 European countries. Am J Respir Crit Care Med 2018; 198: 379-386.

10 Günther G, Gomez G B, Lange C, Rupert S, van Leth F; TBNET. Availability, price and affordability of antituberculosis drugs in Europe: a TBNET survey. Eur Respir J 2015: 45: 1081-1088.

11 Heyckendorf J, van Leth F, Kalsdorf B, et al. Relapse-free cure from multidrug-resistant tuberculosis in Germany. Eur Respir J 2018: 51: 1702122.

12 Lange C, Alghamdi W A, Al-Shaer M H, et al. Perspectives for personalized therapy for patients with multidrug-resistant tuberculosis. J Intern Med 2018 May 28. [Epub ahead of print]

13 Ahmad A, Ahuja S D, Ackermann O W, et al. Treatment correlates of successful outcomes in pulmonary multidrugresistant tuberculosis-an individual patient data metaanalysis of 12,030 patients from 25 countries. Lancet 2018; 392: 821-834.

14 World Health Organization. The use of molecular line probe assays for the detection of resistance to second-line antituberculosis drugs. Policy guidance. WHO/HTM/TB/2016. 07. Geneva, Switzerland: WHO, 2016.

15 World Health Organization. The use of molecular line-probe assays for the detection of resistance to isoniazid and rifampicin. Policy update. WHO/HTM/TB/2016.12. Geneva, Switzerland: WHO, 2016.

16 Miotto P, Tessema B, Tagliani E, et al. A standardised method for interpreting the association between mutations and phenotypic drug resistance in Mycobacterium tuberculosis. Eur Respir J 2017; 50: 1701354.

17 Zignol M, Cabibbe A M, Dean A S, et al. Genetic sequencing for surveillance of drug resistance in tuberculosis in highly endemic countries: a multi-country population-based surveillance study. Lancet Infect Dis 2018; 18: 675-683.

18 Coll F, Phelan J, Hill-Cawthorne G A, et al. Genome-wide analysis of multi- and extensively drug-resistant Mycobacterium tuberculosis. Nat Genet 2018; 50: 307-316.

19 World Health Organization. Technical Report on critical concentrations for drug susceptibility testing of medicines used in the treatment of drug-resistant tuberculosis. WHO/ CDS/TB/2018.5. Geneva, Switzerland: WHO, 2018.

20 Manson A L, Cohen K A, Abeel T, et al. Genomic analysis of globally diverse Mycobacterium tuberculosis strains provides insights into the emergence and spread of multidrug resistance. Nat Genet 2017; 49: 395-402.

21 Walker T M, Kohl T A, Omar S V, et al. Whole-genome sequencing for prediction of Mycobacterium tuberculosis drug susceptibility and resistance: a retrospective cohort study. Lancet Infect Dis 2015; 15: 1193-1202. 
22 Allix-Beguec C, Arandjelovic I, Bi L, et al. Prediction of susceptibility to first-line tuberculosis drugs by DNA sequencing. N Engl J Med 2018; 379: 1403-1415.

23 van Ingen J, Aarnoutse R, de Vries G, Boeree M J, van Soolingen D. Low-level rifampicin-resistant Mycobacterium tuberculosis strains raise a new therapeutic challenge. Int Tuberc Lung Dis 2011; 15: 990-992.

24 Miotto P, Cabibbe A M, Borroni E, Degano M, Cirillo D M. Role of disputed mutations in the rpoB gene in interpretation of automated liquid MGIT culture results for rifampin susceptibility testing of Mycobacterium tuberculosis. J Clin Microbiol 2018; 56: e01599-17.

25 Williamson D A, Roberts S A, Bower J E, et al. Clinical failures associated with rpoB mutations in phenotypically occult multidrug-resistant Mycobacterium tuberculosis. Int J Tuberc Lung Dis 2012; 16: 216-220.

26 Van Deun A, Barrera L, Bastian I, et al. Mycobacterium tuberculosis strains with highly discordant rifampin susceptibility test results. J Clin Microbiol 2009: 47: 35013506.

27 Ho J, Jelfs P, Sintchencko V. Phenotypically occult multidrugresistant Mycobacterium tuberculosis: dilemmas in diagnosis and treatment. J Antimicrob Chemother 2013; 68: 29152920.

28 Jamieson F B, Guthrie J L, Neemuchwala A, Lastovetska O, Melano R G, Mehaffy C. Profiling of rpoB mutations and MICs for rifampin and rifabutin in Mycobacterium tuberculosis. J Clin Microbiol 2014; 52: 2157-2162.

29 Schon T, Jureen P, Chryssanthou E, et al. Rifampicin-resistant and rifabutin-susceptible Mycobacterium tuberculosis strains: a breakpoint artefact? J Antimicrob Chemother 2013; 68: 2074-2077.

30 Gonzalo X, Claxton P, Brown T, et al. True rifampicin resistance missed by the MGIT: prevalence of this pheno/ genotype in the UK and Ireland after 18 month surveillance. Clin Microbiol Infect 2017; 23: 260-263.

31 Andre E, Goeminne L, Cabibbe A, et al. Consensus numbering system for the rifampicin resistance-associated rpoB gene mutations in pathogenic mycobacteria. Clin Microbiol Infect 2017; 23: 167-172.

32 Doyle R M, Burgess C, Williams R, et al. Direct whole genome sequencing of sputum accurately identifies drug resistant Mycobacterium tuberculosis faster than MGIT culture sequencing. J Clin Microbiol 2018; 56: e00666-18.

33 Moore D F, Guzman J A, Mikhail L T. Reduction in turnaround time for laboratory diagnosis of pulmonary tuberculosis by routine use of a nucleic acid amplification test. Diagn Microbiol Infect Dis 2005; 52: 247-254.

34 Votintseva A A, Bradley P, Pankhurst L, et al. Same-day diagnostic and surveillance data for tuberculosis via wholegenome sequencing of direct respiratory samples. J Clin Microbiol 2017; 55: 1285-1298.

35 World Health Organization. GLI practical guide to TB laboratory strengthening. Geneva, Switzerland: WHO, 2017.

36 Hawkins R C. Laboratory turnaround time. Clin Biochem Rev 2007; 28: 179-194.

37 Heysell S K, Pholwat S, Mpagama S G, et al. Sensititre MycoTB plate compared to Bactec MGIT 960 for first- and second-line antituberculosis drug susceptibility testing in Tanzania: a call to operationalize MICs. Antimicrob Agents Chemother 2015; 59: 7104-7108.

38 Abuali M M, Katariwala R, LaBombardi V J. A comparison of the Sensititre ${ }^{\circledR}$ MYCOTB panel and the agar proportion method for the susceptibility testing of Mycobacterium tuberculosis. Eur J Clin Microbiol Infect Dis 2012: 31: 835839.

39 Steingart K R, Schiller I, Horne D J, Pai M, Boehme C C, Dendukuri N. Xpert ${ }^{\circledR}$ MTB/RIF assay for pulmonary tuberculosis and rifampicin resistance in adults. Cochrane Database Syst Rev 2014; (1): CD009593.

40 Dorman S E, Schumacher S G, Alland D, et al. Xpert MTB/RIF Ultra for detection of Mycobacterium tuberculosis and rifampicin resistance: a prospective multicentre diagnostic accuracy study. Lancet Infect Dis 2018: 18: 76-84.

41 Quan T P, Bawa Z, Foster D, et al. Evaluation of wholegenome sequencing for mycobacterial species identification and drug susceptibility testing in a clinical setting: a large-scale prospective assessment of performance against line probe assays and phenotyping. J Clin Microbiol 2018; 56: e0148017.

42 Ruesen C, Riza A L, Florescu A, et al. Linking minimum inhibitory concentrations to whole genome sequencepredicted drug resistance in Mycobacterium tuberculosis strains from Romania. Sci Rep 2018; 8: 9676.

43 Heyckendorf J, Andres S, Koser C U, et al. What is resistance? Impact of phenotypic versus molecular drug resistance testing on therapy for multi- and extensively drug-resistant tuberculosis. Antimicrob Agents Chemother 2018; 62: e01550-17.

44 Cabibbe A M, Trovato A, De Filippo M R, et al. Countrywide implementation of whole genome sequencing: an opportunity to improve tuberculosis management, surveillance and contact tracing in low incidence countries. Eur Respir J 2018; 51: 1800387.

45 Yang Y, Niehaus K E, Walker T M, et al. Machine learning for classifying tuberculosis drug-resistance from DNA sequencing data. Bioinformatics 2018: 34: 1666-1671.

46 Hofmann-Thiel S, Hoffmann H, Hillemann D, Rigouts L, Van Deun A, Kranzer K. How should discordance between molecular and growth-based assays for rifampicin resistance be investigated? Int J Tuberc Lung Dis 2017; 21: 721-726.

47 Dominguez J, Boettger E C, Cirillo D, et al. Clinical implications of molecular drug resistance testing for Mycobacterium tuberculosis: a TBNET/RESIST-TB consensus statement. Int J Tuberc Lung Dis 2016; 20: 24-42.

48 Molina-Moya B, Lacoma A, Prat C, et al. AID TB resistance line probe assay for rapid detection of resistant Mycobacterium tuberculosis in clinical samples. J Infect 2015; 70: 400-408.

49 Nathavitharana R R, Cudahy P G, Schumacher S G, Steingart K R, Pai M, Denkinger C M. Accuracy of line probe assays for the diagnosis of pulmonary and multidrug-resistant tuberculosis: a systematic review and meta-analysis. Eur Respir J 2017; 49: 1601075.

50 Theron G, Peter J, Richardson M, Warren R, Dheda K, Steingart K R. GenoType ${ }^{\circledR}$ MTBDRsl assay for resistance to second-line anti-tuberculosis drugs. Cochrane Database Syst Rev 2016; (9): CD010705.

51 World Health Organization. WHO consolidated guidelines on drug-resistant tuberculosis treatment. WHO/CDS/TB/2019.7. Geneva, Switzerland: WHO, 2019.

52 Diacon A H, Pym A, Grobusch M P, et al. Multidrug-resistant tuberculosis and culture conversion with bedaquiline. $\mathrm{N}$ Engl J Med 2014; 371: 723-732.

53 Alsultan A, Peloquin C A. Therapeutic drug monitoring in the treatment of tuberculosis: an update. Drugs 2014; 74: 839854. [Erratum appears in Drugs 2014; 74: 1061].

54 Peloquin $\mathrm{C}$. The role of therapeutic drug monitoring in mycobacterial infections. Microbiol Spectr 2017 Jan; 5 (1).

55 Alffenaar J W C, Gumbo T, Aarnoutse R E. Acquired drug resistance: we can do more than we think! (Correspondence). Clin Infect Dis 2015; 60: 969-970.

56 Nahid P, Dorman S E, Alipanah N, et al. Officical American Thoracic Society/Centers for Disease Control and Prevention/ Infectious Diseases Society of America clinical practice guidelines: treatment of drug-susceptible tuberculosis. Clin Infect Dis 2016; 63: 853-867. 
57 Magis-Escurra C, Later-Nijland H M, Alffenaar J W, et al. Population pharmacokinetics and limited sampling strategy for first-line tuberculosis drugs and moxifloxacin. Int J Antimicrob Agents 2014; 44: 229-234.

58 Vu D H, Alffenaar J W, Edelbroek P M, Brouwers J R, Uges D R. Dried blood spots: a new tool for tuberculosis treatment optimization. Curr Pharm Des 2011: 17: 2931-2939.

59 Aarnoutse R E, Sturkenboom M G, Robijns K, et al. An interlaboratory quality control programme for the measurement of tuberculosis drugs. Eur Respir J 2015: 46: 268-271.

60 van Heeswijk R P, Dannemann B, Hoetelmans R M. Bedaquiline: a review of human pharmacokinetics and drugdrug interactions. J Antimicrob Chemother 2014; 69: 2310 2318

61 Svensson E M, Dosne A G, Karlsson M O. Population pharmacokinetics of bedaquiline and metabolite M2 in patients with drug-resistant tuberculosis: the effect of timevarying weight and albumin. CPT Pharmacometrics Syst Pharmacol 2016; 5: 682-691.

62 Svensson E M, Karlsson M O. Modelling of mycobacterial load reveals bedaquiline's exposure-response relationship in patients with drug-resistant TB J Antimicrob Chemother 2017; 72: 3398-3405.

63 Magis-Escurra C, Later-Nijland H M, Alffenaar J W, et al. Population pharmacokinetics and limited sampling strategy for first-line tuberculosis drugs and moxifloxacin. Int $\mathrm{J}$ Antimicrob Agents 2014; 44: 229-234.

64 Boeree M J, Diacon A H, Dawson R, et al. A dose-ranging trial to optimize the dose of rifampin in the treatment of tuberculosis. Am J Respir Crit Care Med 2015; 191: 10581065.

65 Boeree M J, Heinrich N, Aarnoutse R, et al. High-dose rifampicin, moxifloxacin, and SQ109 for treating tuberculosis: a multi-arm, multi-stage randomised controlled trial. Lancet Infect Dis 2017; 17: 39-49.

66 Bloss E, Kukša L, Holtz T H, et al. Adverse events related to multidrug-resistant tuberculosis treatment, Latvia, 20002004. Int J Tuberc Lung Dis 2010: 14: 275-281.

67 Curry International Tuberculosis Centre \& California Department of Public Health. Drug-resistant tuberculosis. A survival guide for clinicians. $3^{\text {rd }}$ ed. San Fransisco, CA, USA: CITC \& the State of California Department of Public Health, Tuberculosis Control Branch (CDPH), 2016.

68 World Health Organization. WHO treatment guidelines for drug-resistant tuberculosis. 2016 update. WHO/HTM/TB/ 2016.04. Geneva, Switzerland: WHO, 2016.

69 Jenkins H E, Yuen C M. The burden of multidrug-resistant tuberculosis in children. Int J Tuberc Lung Dis 2018; 22: 3-6.

70 World Health Organization. Latent tuberculosis infection: updated and consolidated guidelines for programmatic management. WHO/CDS/TB/2018.4. Geneva, Switzerland: WHO, 2018.

71 Weld E D, Garcia-Prats A J, Furin J J, Bailey T C, Hesseling A C, Dooley K E. The time has come: sparing injectables in paediatric MDR-TB. Lancet Respir Med 2017: 5: 245-246.

72 Seddon J A, Thee S, Jacobs K, Ebrahim A, Hesseling A C, Schaaf H S. Hearing loss in children treated for multidrugresistant tuberculosis. J Infect 2013; 66: 320-329.

73 Furin J, Tommasi M, Garcia-Prats A J. Drug-resistant tuberculosis: will grand promises fail children and adolescents? Lancet Child Adolesc Health 2018; 2: $237-$ 238.

74 Garcia-Prats A J, Svensson E M, Weld E D, Schaaf H S, Hesseling A C. Current status of pharmacokinetic and safety studies of multidrug-resistant tuberculosis treatment in children. Int J Tuberc Lung Dis 2018; 22: 15-23.

75 Pai M, Furin J. Tuberculosis innovations mean little if they cannot save lives. Elife 2017; 6: e25956.
76 Dheda K, Gumbo T, Maartens G, et al. The epidemiology, pathogenesis, transmission, diagnosis, and management of multidrug-resistant, extensively drug-resistant, and incurable tuberculosis. Lancet Respir Med 2017 Mar 15. [Epub ahead of print].

77 Gegia M, Winters N, Benedetti A, van Soolingen D, Menzies D. Treatment of isoniazid-resistant tuberculosis with first-line drugs: a systematic review and meta-analysis. Lancet Infect Dis 2017; 17: 223-234.

78 Tomasicchio M, Theron G, Pietersen E, et al. The diagnostic accuracy of the MTBDRplus and MTBDRsl assays for drugresistant TB detection when performed on sputum and culture isolates. Sci Rep 2016; 6: 17850.

79 Dheda K, Cox H, Esmail A, Wasserman S, Chang K C, Lange C. Recent controversies about MDR and XDR-TB: Global implementation of the WHO shorter MDR-TB regimen and bedaquiline for all with MDR-TB? Respirology 2018; 23: 3645 .

80 Lange C, Chesov D, Heyckendorf J, Leung CC, Udwadia Z, Dheda K. Drug-resistant tuberculosis: an update on disease burden, diagnosis and treatment. Respirology 2018; 23: 656673.

81 Schnippel K, Ndjeka N, Maartens G, et al. Effect of bedaquiline on mortality in South African patients with drug-resistant tuberculosis: a retrospective cohort study. Lancet Respir Med 2018; 6: 699-706.

82 Zimenkov D V, Nosova E Y, Kulagina E V, et al. Examination of bedaquiline- and linezolid-resistant Mycobacterium tuberculosis isolates from the Moscow region. J Antimicrob Chemother 2017; 72: 1901-1906.

83 Olayanju O, Limberis J, Esmail A, et al. Long-term bedaquiline-related treatment outcomes in patients with extensively drug-resistant tuberculosis from South Africa. Eur Respir J 2018; 51: 1800544.

84 Dheda K, Migliori G B. The global rise of extensively drugresistant tuberculosis: is the time to bring back sanatoria now overdue? Lancet 2012; 379: 773-775.

85 Mesfin Y M, Hailemariam D, Biadgilign S, Kibret $\mathrm{K}$ T. Association between HIV/AIDS and multi-drug resistance tuberculosis: a systematic review and meta-analysis. PLOS ONE 2014; 9: e82235.

86 Magis-Escurra C, Gunther G, Lange C, et al. Treatment outcomes of MDR-TB and HIV co-infection in Europe. Eur Respir J 2017; 49: 1602363.

87 Dooley K E, Sayre P, Borland J, et al. Safety, tolerability, and pharmacokinetics of the HIV integrase inhibitor dolutegravir given twice daily with rifampin or once daily with rifabutin: results of a phase 1 study among healthy subjects. J Acquir Immune Defic Syndr 2013; 62: 21-27.

88 Svensson E M, Dooley K E, Karlsson M O. Impact of lopinavir-ritonavir or nevirapine on bedaquiline exposures and potential implications for patients with tuberculosis-HIV coinfection. Antimicrob Agents Chemother 2014; 58: 64066412.

89 Pandie M, Wiesner L, McIlleron $\mathrm{H}$, et al. Drug-drug interactions between bedaquiline and the antiretrovirals lopinavir/ritonavir and nevirapine in HIV-infected patients with drug-resistant TB. J Antimicrob Chemother 2016; 71: 1037-1040.

90 Torok M E, Yen N T, Chau T T, et al. Timing of initiation of antiretroviral therapy in human immunodeficiency virus (HIV)—associated tuberculous meningitis. Clin Infect Dis 2011; 52: 1374-1383.

91 Meintjes G, Stek C, Blumenthal L, et al. Prednisone for the prevention of paradoxical tuberculosis-associated IRIS. N Engl J Med 2018; 379: 1915-1925.

92 Riza A L, Pearson F, Ugarte-Gil C, et al. Clinical management of concurrent diabetes and tuberculosis and the implications 
for patient services. Lancet Diabetes Endocrinol 2014; 2: 740 753.

93 Degner N R, Wang J Y, Golub J E, Karakousis P C. Metformin use reverses the increased mortality associated with diabetes mellitus during tuberculosis treatment. Clin Infect Dis 2018; 66: 198-205.

94 Faurholt-Jepsen D, Range N, PrayGod G, et al. Diabetes is a strong predictor of mortality during tuberculosis treatment: a prospective cohort study among tuberculosis patients from Mwanza, Tanzania. Trop Med Int Health 2013; 18: 822-829.

95 van Crevel R, Koesoemadinata R, Hill P C, Harries A D. Clinical management of combined tuberculosis and diabetes. Int J Tuberc Lung Dis 2018; 22: 1404-1410.

96 Zhao J N, Zhang X X, He X C, et al. Multidrug-resistant tuberculosis in patients with chronic obstructive pulmonary disease in China. PLOS ONE 2015; 10: e0135205.

97 Allwood B W, van Zyl-Smit R. Tuberculosis, chronic obstructive pulmonary disease and inhaled corticosteroids: a complex web. Int J Tuberc Lung Dis 2017: 21: 1317-1318.

98 Amere G A, Nayak P, Salindri A D, Venkat Narayan K M, Magee M J. Contribution of smoking to tuberculosis incidence and mortality in high tuberculosis burden countries. Am J Epidemiol 2018; 187: 1846-1855.

99 O'Leary S M, Coleman M M, Chew W M, et al. Cigarette smoking impairs human pulmonary immunity to Mycobacterium tuberculosis. Am J Respir Crit Care Med 2014; 190: 1430-1436.

100 Wang M G, Huang W W, Wang Y, et al. Association between tobacco smoking and drug-resistant tuberculosis. Infect Drug Resist 2018; 11: 873-887.

101 Reimann M, Schaub D, Kalsdorf B, et al. Cigarette smoking and culture conversion in patients with susceptible and $\mathrm{M} /$ XDR-TB. Int J Tuberc Lung Dis 2019; 23: 93-98.

102 Sharma S K, Mohan A, Singh A D, et al. Impact of nicotine replacement therapy as an adjunct to anti-tuberculosis treatment and behaviour change counselling in newly diagnosed pulmonary tuberculosis patients: an open-label, randomised controlled trial. Sci Rep 2018; 8: 8828.

103 Jeyashree K, Kathirvel S, Shewade H D, Kaur H, Goel S. Smoking cessation interventions for pulmonary tuberculosis treatment outcomes. Cochrane Database Syst Rev 2016; (1): CD011125

104 Louwagie G M, Okuyemi K S, Ayo-Yusuf O A. Efficacy of brief motivational interviewing on smoking cessation at tuberculosis clinics in Tshwane, South Africa: a randomized controlled trial. Addiction 2014; 109: 1942-1952.

105 Ravimohan S, Kornfeld H, Weissman D, Bisson G P. Tuberculosis and lung damage: from epidemiology to pathophysiology. Eur Respir Rev 2018; 27: 170077.

106 Munoz-Torrico M, Rendon A, Centis R, et al. Is there a rationale for pulmonary rehabilitation following successful chemotherapy for tuberculosis? J Bras Pneumol 2016; 42: 374-385.

107 Bott J, Blumenthal S, Buxton M, et al. Guidelines for the physiotherapy management of the adult, medical, spontaneously breathing patient. Thorax 2009; 64 (Suppl 1): i1-51.

108 Spruit M A, Singh S J, Garvey C, et al. An official American Thoracic Society/European Respiratory Society statement: key concepts and advances in pulmonary rehabilitation. Am J Respir Crit Care Med 2013; 188: e13-64.

109 World Health Organization. Ethics guidance for the implementation of the End TB strategy. WHO/HTM/TB/ 2017.07. Geneva, Switzerland: WHO, 2017.

110 World Health Organization. The role of surgery in the treatment of pulmonary TB and multidrug- and extensively drug-resistant TB. Copenhagen, Denmark: World Health Organization European Region Office, 2014.
111 Subotic D, Yablonskiy P, Sulis G, et al. Surgery and pleuropulmonary tuberculosis: a scientific literature review. J Thorac Dis 2016; 8: E474-485.

112 Fox G J, Mitnick C D, Benedetti A, et al. Surgery as an adjunctive treatment for multidrug-resistant tuberculosis: an individual patient data metaanalysis. Clin Infect Dis 2016; 62: 887-895.

113 Yablonskii P, Kudriashov G, Vasilev I, Avetisyan A, Sokolova O. Robot-assisted surgery in complex treatment of the pulmonary tuberculosis. J Vis Surg 2017; 3: 18.

114 Nunn A J, Phillips P P J, Meredith S K, et al. A trial of a shorter regimen for rifampin-resistant tuberculosis. N Engl J Med 2019; 380: 1201-1213.

115 Lange C, Duarte R, Frechet-Jachym M, et al. Limited benefit of the new shorter multidrug-resistant tuberculosis regimen in Europe. Am J Respir Crit Care Med 2016; 194: 1029-1031.

116 Guglielmetti L, Jaspard M, Le Du D, et al. Long-term outcome and safety of prolonged bedaquiline treatment for multidrugresistant tuberculosis. Eur Respir J 2017; 49: 1601799.

117 Heyckendorf J, Olaru I D, Ruhwald M, Lange C. Getting personal perspectives on individualized treatment duration in multidrug-resistant and extensively drug-resistant tuberculosis. Am J Respir Crit Care Med 2014; 190: 374-383.

118 Laserson K F, Thorpe L E, Leimane V, et al. Speaking the same language: treatment outcome definitions for multidrugresistant tuberculosis. Int J Tuberc Lung Dis 2005; 9: 640645.

119 World Health Organization. Definitions and reporting framework for tuberculosis-2013 revision. Updated December 2014. WHO/HTM/TB/2013.2. Geneva, Switzerland: WHO, 2014.

120 Dooley K E, Phillips P P, Nahid P, Hoelscher M. Challenges in the clinical assessment of novel tuberculosis drugs. Adv Drug Deliv Rev 2016; 102: 116-122.

121 Phillips P P, Dooley K E, Gillespie S H, et al. A new trial design to accelerate tuberculosis drug development: the Phase IIC Selection Trial with Extended Post-treatment follow-up (STEP). BMC Med 2016; 14: 51.

122 Günther G, Lange C, Alexandru S, et al. Treatment outcomes in multidrug-resistant tuberculosis. N Engl J Med 2016; 375 : 1103-1105.

123 Lange C, van Leth F, Mitnick C D, Dheda K, Gunther G. Time to revise WHO-recommended definitions of MDR-TB treatment outcomes. Lancet Respir Med 2018; 6: 246-248.

124 Migliori G B; Global Tuberculosis Network. Evolution of programmatic definitions used in tuberculosis prevention and care. Clin Infect Dis 2018; Nov 20. [Epub ahead of print]

125 Diacon A H, Van Baelen B, Theeuwes M. More on treatment outcomes in multidrug-resistant tuberculosis. N Engl J Med 2016; 375: 2609-2610.

126 Chesov D, Alexandru S, Crudu V, et al. Failing treatment of multidrug-resistant tuberculosis: a matter of definition. Int J Tuberc Lung Dis 2019; 23: 522-524.

127 Mack U, Migliori G B, Sester M, et al. LTBI: latent tuberculosis infection or lasting immune responses to $M$. tuberculosis? A TBNET consensus statement. Eur Respir J 2009; 33: 956-973.

128 Shah N S, Yuen C M, Heo M, Tolman A W, Becerra M C. Yield of contact investigations in households of patients with drugresistant tuberculosis: systematic review and meta-analysis. Clin Infect Dis 2014; 58: 381-391.

129 Marks S M, Mase S R, Morris S B. Systematic review, metaanalysis, and cost-effectiveness of treatment of latent tuberculosis to reduce progression to multidrug-resistant tuberculosis. Clin Infect Dis 2017; 64: 1670-1677.

130 Garcia-Prats A J, Draper H R, Finlayson H, et al. Clinical and cardiac safety of long-term levofloxacin in children treated for multidrug-resistant tuberculosis. Clin Infect Dis 2018; 67: $1777-1780$. 
131 Dheda K, Lenders L, Magombedze G, et al. Drug penetration gradients associated with acquired drug resistance in tuberculosis patients. Am J Respir Crit Care Med 2018; 198: 1208-1219.

132 Lange C, Chesov D, Furin J, Udwadia Z, Dheda K. Revising the definition of extensively drug-resistant tuberculosis. Lancet Respir Med 2018; 6: 893-895.
133 Calligaro G L, Zijenah L S, Peter J G, et al. Effect of new tuberculosis diagnostic technologies on community-based intensified case finding: a multicentre randomised controlled trial. Lancet Infect Dis 2017; 17: 441-450.

134 Dheda K, Barry C E, $3^{\text {rd }}$, Maartens G. Tuberculosis. Lancet 2016; 387: 1211-1226. 
L'émergence de la tuberculose multirésistante (MDRTB: résistance à la rifampicine et à l'isoniazide) représente une menace croissante pour la santé publique et la croissance économique. Jamais auparavant dans histoire de l'humanité, autant de patients n'avaient été affectés par la MDR-TB comme c'est le cas aujourd'hui. L'Organisation Mondiale de la Santé rapporte que les résultats de la MDR-TB sont médiocres en dépit de coûts de prise en charge vertigineux. Plus encore, le traitement est considérablement prolongé, les effets secondaires sont fréquents et la majorité des patients affectés ne reçoit pas un traitement suffisant. Comme les souches de MDR Mycobacterium tuberculosis sont souvent résistantes à un ou plusieurs médicaments anti-TB de deuxième ligne, un test de pharmacosensibilité approfondi, génotypique et phénotypique, est obligatoire pour créer des protocoles de traitement individualisés, sur mesure, ce qui favorisera de meilleurs résultats du traitement. Avec la disponibilité de nouveaux médicaments comme la bédaquiline, pour la première fois depuis des décennies, on peut maintenant concevoir des protocoles de traitement de la MDR-TB, personnalisés, puissants et bien tolérés, ne comprenant que des médicaments oraux. Ce document fournit une guidance à la prise en charge afin d'optimiser le diagnostic, le traitement basé sur des algorithmes, le choix de la posologie, le suivi du traitement et la prise en charge des effets secondaires ainsi que les comorbidités associées avec la MDR-TB et leurs contacts. Nous discutons également le rôle de la chirurgie, de la physiothérapie, de la rééducation, des soins palliatifs et de l'arrêt du tabac chez les patients atteints de MDR-TB. Incorporer ces recommandations aux soins des patients devrait contribuer à optimiser les résultats du traitement et aboutir à une plus grande proportion de patients MDR-TB qui obtiennent une guérison sans rechute.
La aparición de la tuberculosis multirresistente (MDR$\mathrm{TB}$; resistente a rifampicina e isoniazida) representa una amenaza cada vez mayor de salud pública y al crecimiento económico. Nunca antes en la historia de la humanidad habían existido tantos pacientes afectados por la TB-MDR como en la actualidad. La Organización Mundial de la Salud informa que los desenlaces de la TB-MDR son desfavorables, pese a los abrumadores costos de su manejo. Además, la duración del tratamiento es sumamente prolongada, las reacciones adversas son frecuentes y la mayoría de los pacientes afectados no recibe un tratamiento adecuado. Dado que las cepas MDR de Mycobacterium tuberculosis suelen ser resistentes a uno o varios medicamentos antituberculosos de segunda línea, es obligatorio realizar pruebas genotípicas y fenotípicas de sensibilidad exhaustivas, con el fin de construir esquemas terapéuticos adaptados a cada persona, lo cual se favorece la obtención de mejores resultados del tratamiento. Con la puesta a disposición de nuevos fármacos como la bedaquilina, por primera vez en varios decenios, se pueden construir hoy esquemas terapéuticos de la TB-MDR personalizados y bien tolerados, que solo comportan fármacos administrados por vía oral. El presente documento ofrece directrices de manejo que facilitan la optimización del diagnóstico, el tratamiento basado en un algoritmo, la pauta posológica, la farmacovigilancia terapéutica y la gestión de los contactos. Se analiza también la función de la cirugía, la fisioterapia, la rehabilitación, los cuidados paliativos y el abandono del tabaquismo en los pacientes con TBMDR. Se espera que al incorporar estas recomendaciones en la atención de los pacientes, se optimicen los desenlaces terapéuticos y que los pacientes con TB-MDR alcancen con mayor frecuencia la curación sin recaída. 